Polonca KOVAČ, Lan UMEK, Dejan RAVŠELJ, Aleksander ARISTOVNIK*

\title{
IMPACT OF COVID-19 ON THE DIGITALISATION OF ADMINISTRATIVE PROCEDURES: LESSONS FROM SLOVENIAN ADMINISTRATIVE UNITS**
}

\begin{abstract}
The Covid-19 pandemic has transformed our society, with administrative procedures - as relationships between public authorities and citizens and businesses - being no exception. Still, the innovative digitalisation of such procedures means the 58 administrative units across Slovenia have been able to develop a responsive administrative system. Using normative, descriptive and statistical research methods, the article identifies the relevant drivers and barriers, like user demands leading to a more responsive service, the lack of legal bases, and the top-down approach discouraging progress. Correlation analysis shows that digitalisation also holds important positive implications for the principles of good governance. Moreover, larger administrative units are more likely to achieve a higher degree of digitalisation and hence better public governance. The findings are useful for designing evidence-based public policies to properly respond to pandemic-associated challenges.
\end{abstract}

Keywords: public administration, administrative procedures, Covid-19, good public governance, innovation, digitalisation, Slovenia

\section{Introduction}

With the spread of the new virus and adoption of related government measures in 2020, the Covid-19 pandemic has affected virtually every dimension of social life, including administrative relations. The latter involve the

* Polonca Kovač, PhD, Professor, Faculty of Public Administration, University of Ljubljana, Slovenia; Lan Umek, PhD, Assistant Professor, Faculty of Public Administration, University of Ljubljana, Slovenia; Dejan Ravšelj, PhD, Researcher, Faculty of Public Administration, University of Ljubljana, Slovenia; Aleksander Aristovnik, PhD, Professor, Faculty of Public Administration, University of Ljubljana, Slovenia.

** This article is a result of the basic research projects "The Development of a Holistic Governance Model for an Efficient and Effective Slovenian Public Administration" (J5-8238) and "Transformation of Governance and Public Service Delivery Mechanisms in the Digital Age" (J5-1789), as well as the research programme "Development of an Efficient and Effective Public Administration System" (P5-0093). The authors acknowledge the financial support of the Slovenian Research Agency.

DOI: 10.51936/tip.58.specialissue.652-669 
rights exercised and obligations imposed in authorities-individuals relationships, such as the collection of taxes, social assistance, building permits etc. A key guideline here - in both public policy design and legal regulation of administrative procedures, and the implementing of the rules in practice - is to ensure a balance between protection of the public interest and the rights of public services users, i.e. citizens and businesses as parties in the procedure. This means there is a constant weighing up of legality and legal certainty on one hand and flexibility and innovation on the other (Hofmann et al., 2014; Kovač and Kerševan, 2020). The mentioned guideline also applies to the context of the Covid-19 pandemic, although it seems the relevant approaches are increasingly leaning towards innovation with a view to ensuring greater responsiveness. Although administrative procedures are legally determined and thus somewhat rigid, scholars have long studied the right ratio between the determinateness of the rules and innovative responsiveness to societal needs (Stewart, 1981; Metzger, 2005; Kovač et al., 2016). Accordingly, striving for good public governance entails a fusion of socio-political, legal, organisational and economic theories, practice, and general administrative dilemmas.

In this context, the digitalisation of public administration - seen as a tool for development and responding to rapidly changing community needs - is hugely important in both the EU and at the level of individual countries. As such, it should not be a goal in and of itself. A key aspect of digital transformation in the administrative setting is e-communication, i.e. internally, between authorities and employees, and externally, in the relations with public services users (Misuraca, 2019). As already observed in the first wave of the pandemic in the spring of 2020, a crisis requires not just a revision of but a radical shift away from the existing codification and modus operandi, particularly in transition countries. This is revealed by the established strengths and weaknesses of individual countries regarding their democratic and governance capacity-related responses (Sigma, 2020; Bouckaert et al., 2020; cf. Kukovič and Justinek, 2020). Administrative procedures are traditionally governed quite rigidly by a general law which - regardless of sectoral specificities (e.g. in taxes, social affairs, the environment) - gives effect to the constitutional and international principles of good governance (Galetta et al., 2015; Avbelj, 2019). In such a context, good governance and to a certain extent also "digital-era governance" - are taken as reform approaches to upgrade the classical doctrines of Weber and New Public Management (Kukovič and Justinek, 2020).

In Slovenia, the general law on administrative procedures is the General Administrative Procedure Act (GAPA), applicable since April 2000. ${ }^{1}$ Being

1 Official Gazette of the Republic of Slovenia (OGRS), No. 80/99 and amendments. Slovenia became independent in 1991 after the breakup of Yugoslavia and has been a full member of the EU since 2004. 
a successor to the old Yugoslav (1956) and Austrian (1925) laws, the GAPA has limited coverage of contemporary concepts (Rose-Ackermann and Lindseth, 2010; van der Hof and Groothuis, 2011; Kovač, 2020). In particular, comparatively speaking, Slovenian law appears to be highly formalised instead of containing targeted general provisions and addressing - in view of the modern wide range of different administrative acts issued by administrative bodies - more than just single-case decision-making.

Accordingly, the research question posed herein is how Slovenia and its administrative bodies have responded to the pandemic and how appropriate their response has been in terms of lasting improvements. To comprehensively analyse the efforts and results in this field, an applied case study was launched in the summer of 2020 among the 58 administrative units (AUs). The AUs are general bodies on the territorial level that annually run around 1 million procedures in various sectors, accounting for one-tenth of all such procedures on the national scale. This makes it justified to expect that their experiences can provide a sound platform for future evidencebased decision-making, leading to (more) digitalised and hence efficient administrative work based on innovative, yet legally sound approaches. The hypotheses tested herein are H1: Public services users' expectations are largely contributing to the greater digitalisation of communication in administrative matters, and H2: The legal framework for administrative procedures in Slovenia requires a higher degree of innovative codification and systemic digitalisation to respond to crises like the Covid-19 pandemic. The article aims to analyse the work of Slovenian AUs during the pandemic in order to identify what affects those engaged in the proceedings and how to improve the legal regulation and related measures while pursuing the principles of good governance. The theoretical definition of the characteristics of administrative procedures and associated understanding of innovation and digitalisation in this area are followed by an outline of the methodological concept of research in Slovenian AUs and a presentation of the results of analyses. This leads to a discussion of the results and their comparison against the two hypotheses along with some general recommendations, followed by a conclusion.

\section{Digitalisation as an innovative approach in Slovenian administrative relations}

Certain features of administrative relations compared to the private sector must be considered while introducing innovation and digitalisation.

However, the EU allows member states to regulate their administrative procedures autonomously, despite certain convergence at the EU level (Hofmann et al., 2014; Kovač, 2016). 
Namely, in public administration, the legal positions held by individuals, businesses and other public services users are often interfered with by the authorities in the name of the public interest, thereby making these relationships legally determined while limiting innovation (Rose-Ackerman and Lindseth, 2010: 339; Vigoda, 2002: 528). This is especially true in transition countries because the internalisation of systemic changes and sustainable and inclusive growth usually take decades (Bučar and Stare, 2003: 20-58; Rusch, 2014; Koprić et al., 2016). Digitalisation can even lead to technocracy, not improvement, if the system of values, the rules, and the relations between stakeholders are inadequate (Ranchordas, 2020; Windholz, 2020). In contrast, responsiveness, especially through digitalisation, is not only a quality of private organisations but also serves as a litmus test for the public sphere to check its accountability in relation to the public and the users since it is not in conflict with democratic values. Therefore, innovation and digitalisation are growing trends also in public administration (Torfing and Triantafillou, 2016; Massey, 2019; Misuraca et al., 2020), yet need to be regulated properly to ensure legal predictability and equality (de Vries et al., 2016: 146; Metzger, 2015; Bučar and Stare, 2003: 9).

The rapidly changing circumstances - such as the Covid-19 pandemic, an economic crisis, or a major environmental disaster - call for a search for new balances and the development of resilience to crises (Prezelj and Doerfel, 2017). Given that it is easier to find an innovative approach by simplifying procedures than by lowering standards, administrative procedural law is characterised by the gradual development of innovations, such as e-applications (Bučar and Stare, 2003: 53ff; Torfing and Triantafillou, 2016: 9-13; de Vries et al., 2016: 153). Since (post)transition societies are particularly reluctant to change, another important external driver of administrative innovation is Europeanisation (Rusch, 2014; Koprić et al., 2016). In terms of the codification of administrative procedures, this means more abstract regulation promoting (only) important principles and rules and thus targeted rather than formalistic norms (Vigoda, 2002: 530; Hofmann et al., 2014: 6; Galetta et al.: 2015: 16). ${ }^{2}$ On the contrary, a too-detailed regulation and the lack of a top-down approach act to discourage innovation through digitalisation (Venice, 2011: 8; Kovač, 2020: 855; Bouckaert et al., 2020).

Considering its scope and potential in Slovenia, the digitalisation of procedures is crucial for an innovative approach in public administration, as also deriving from the EU's guidelines and rules (Harlow and Rawlings, 2014: 26). According to OECD analysis, Slovenia shows progress from

2 The Slovenian GAPA contains over 325 articles. The number of articles as such is not an indicator of obsoleteness, yet comparisons show that most administrative procedure laws in the world only have 15 to some tens of articles (Auby, 2014). 
e-government 1.0, i.e. the promotion of administrative simplification since the 1990s, towards fully embracing a digital-government approach as the cornerstone of digital transformation 4.0 or digital-era governance over the last decade (OECD, 2020: 1ff; cf. Misuraca, 2019: 12; Sigma, 2020). Digital development, literacy, and equipment in Slovenia are generally comparable with other European countries. For instance, in early 2020, there were 1.68 million Internet users, accounting for $81 \%$ of Internet penetration among the population of 2 million, including over 1 million users of social media. Slovenia thus has the comparative advantage to "move fast and be agile" on digital government policy (OECD, 2020), also based on Digital Slovenia 2020 - Development Strategy for the Information Society of 2016 and the Public Administration Development Strategy 2015-2020, both adopted with the goal of intensive and innovative ICT use and Internet networking among all segments of society (Kukovič and Justinek, 2020: 636).

The GAPA amendments adopted over the last 20 years in Slovenia and beyond have indeed included digital approaches in the sense of debureacratisation, but these have usually been partial and inconsistent (for more, see: Kovač, 2020; cf. Auby, 2014). The current waves of digitalisation focus on the technical aspects of technology and leave to one side the fact that (digital) government is primarily a social and political phenomenon that requires cultural changes (Ranchordas, 2020). Therefore, the Slovenian GAPA, as it turned out in practice in March 2020, was not the optimal framework for the operation of the AUs in the Covid-19 crisis. Following the example of good practices from abroad, a 'Covid-19 Act' ${ }^{3}$ was adopted in March 2020 as one of the first emergency laws in the country. The latter repealed several aspects of the GAPA, particularly by simplifying the filing of applications and the services, with an emphasis on digital communication. The law only remained in force until June 2020, but in practice it brought major progress by explicitly formalising certain practices not in conflict with the GAPA when the latter is interpreted teleologically and proactively (Kovač and Kerševan, 2020/1: 777). Based on such good experience, the GAPA was amended in late November 2020 to enable the government to simplify the rules by digitalising communications in the event of an emergency. ${ }^{4}$

Digitalisation seems to be a direct response to various principles of good governance, especially the rule of law, transparency, accountability and participation, responsiveness and efficiency (Venice, 2011; Kovač et al., 2016). However, the added value of the good governance concept lies not

3 The Act on Provisional Measures for Judicial, Administrative and Other Public Matters to Cope with the Spread of Infectious Disease SARS-COV-2 (Covid-19), OGRS, No. 36/20, 61/20 (Slovenian abbreviation: ZZUSUDJZ).

4 The Act Determining the Intervention Measures to Mitigate the Consequences of the Second Wave of Covid-19 Epidemic, OGRS, no. 175/20 (Slovenian abbreviation: ZIUOPDVE) 
in pursuing an individual principle on account of the others but to comply with all of them. This makes digitalisation ideal for introducing innovation while still preserving the traditional values of public service. The complexity of administrative relations is another argument to use digitalisation as a cross-boundary tool to proportionally comply with public law guarantees. In this context, Table 1 shows various phenomena in the context of good public administration. A plus sign is added for a moderate impact on the digitalisation of procedures as a mechanism for developing selected principles of good governance (GG), and two pluses are used for a strong stimulating or inhibitory impact.

\section{Table 1: DRIVERS AND BARRIERS OF DIGITALISATION RELATED TO GG PRINCIPLES}

\begin{tabular}{|c|c|c|c|}
\hline $\begin{array}{l}\text { Phenomena/Factors as } \\
\text { - Type of Factor }\end{array}$ & Drivers & Barriers & $\begin{array}{l}\text { Exposed Good Governance } \\
\text { Principles (rule of law, efficiency, } \\
\text { inclusiveness, responsiveness, } \\
\text { consensus, participation, } \\
\text { transparency, accountability) }\end{array}$ \\
\hline $\begin{array}{l}\text { Administrative tradition and } \\
\text { transition - social/cultural }\end{array}$ & & + & $\begin{array}{l}\text { Rule of law (as legalism), (non) } \\
\text { responsiveness }\end{array}$ \\
\hline $\begin{array}{l}\text { Current GAPA codification - } \\
\text { legal }\end{array}$ & & + & $\begin{array}{l}\text { Rule of law, (limited) efficiency and } \\
\text { participation }\end{array}$ \\
\hline COVID provisional law - legal & + & & $\begin{array}{l}\text { Responsiveness, efficiency, rule of } \\
\text { law }\end{array}$ \\
\hline $\begin{array}{l}\text { Europeanisation/role models } \\
\text { abroad - organisational, legal, } \\
\text { cultural }\end{array}$ & + & & $\begin{array}{l}\text { Rule of law (equality), transparency, } \\
\text { inclusiveness, accountability, } \\
\text { efficiency }\end{array}$ \\
\hline $\begin{array}{l}\text { Leaders' attitude - social/ } \\
\text { cultural }\end{array}$ & + & ++ & $\begin{array}{l}\text { Responsiveness but legality as } \\
\text { formalism }\end{array}$ \\
\hline $\begin{array}{l}\text { Stakeholders' expectations/ } \\
\text { demands and (lack of) trust - } \\
\text { ethical }\end{array}$ & ++ & + & Participation, responsiveness \\
\hline $\begin{array}{l}\text { Crises: economic/health/ } \\
\text { environment }\end{array}$ & ++ & & Responsiveness, efficiency \\
\hline $\begin{array}{l}\text { PA centralisation (top-down) - } \\
\text { organisational, financial }\end{array}$ & + & & Efficiency, accountability \\
\hline $\begin{array}{l}\text { Digitalisation as a means } \\
\text { not a goal in itself - ethical, } \\
\text { technological }\end{array}$ & + & & $\begin{array}{l}\text { Rule of law, responsiveness, } \\
\text { participation, efficiency, } \\
\text { accountability etc. }\end{array}$ \\
\hline
\end{tabular}

Source: own analysis, based on Misuraca, 2019; Massey, 2019: 148ff; Kovač et al., 2016; Venice Commission, 2011.

Digitalisation can thus bring positive effects, above all enhanced participation and services innovation, yet it also contributes to risk such as with respect to labour redundancy, technological discrimination, data-protection concerns, and the lack of both citizens' trust and administrative accountability (Misuraca, 2019: 49ff). The above drivers and barriers to innovation 
and digitalisation in public administration also stem from empirical studies, among others in Slovenian AUs (Kovač et al., 2016: 140; cf. Massey, 2019: 150). For instance, according to a 2016 survey among the heads of the AUs, the rule of law and efficiency must also be constantly balanced in digitalised communications. Even before the Covid-19 pandemic, the AUs reported being faced with ever more demanding expectations, including digitalisation, from citizens and businesses, also related to ensuring a harmonised approach across the EU. Hence, to recapitulate: innovation, such as digitalisation, and the administrative procedure with its abstract codifications are concepts that may be combined to create a new synergistic value. However, individual measures must be approached systematically and carefully, even if crises typically require a rapid response. In fact, abandoning the existing procedures without replacing them with other quality control measures could affect the soundness and responsiveness of authority (Stewart, 1981: 1338; cf. Misuraca, 2019; Windholz, 2020).

\section{Methodological framework of the research on Covid-19-related digitalisation}

The methodological design of the study on the measures implemented by Slovenian AUs during the first wave of the Covid-19 pandemic is based on a previously defined research problem and hypotheses. The research's main goal was to identify existing approaches and evaluate them through the prism of compliance with the principles of good governance, thereby exploring the possibility of them being permanently implemented. An online survey questionnaire was sent to the heads of all Slovenian AUs in July 2020. These bodies were chosen because they are normally the first point of contact between public services users and the administration. There are 58 AUs throughout the country that conduct about 100 different types of procedures. The questionnaire was drawn up by a multidisciplinary research group (experts in law, management, statistics) to address the issue comprehensively based on life situations, as digitalisation requires (Misuraca, 2019: 4; Aristovnik et al., 2020: 3). The common thread running through the total of 21 questions divided into 5 thematic sets was a comparison of the ways the AUs worked and conducted procedures during the Covid-19 pandemic vs. their normal operations. A pilot questionnaire was first tested with the Ministry of Public Administration (MPA) as the coordinator of the AUs, and then distributed among the AU heads. The research group paid special attention to the anonymity of respondents' data and to their responsiveness. This led to a 100\% response rate among the respondents, with at least $77 \%$ of responses per question, making the results highly representative. With the assumption of "missing completely at random", 
meaning that the complete cases are a random sample of the originally identified set of cases, a complete case approach was applied to handle missing data issues (Little and Rubin, 2019).

The respondents' subjective perceptions were verified with available objective indicators, measured on a five-point Likert scale (Croasmun and Ostrom, 2011; cf. note under Figure 1). The selected objective indicators capture the different aspects of the digitalisation of the AUs and the level of achievement of the governance principles. Later, correlation analysis, that is, a methodological approach commonly used in public administration research (Miller, 1998), was performed to evaluate the direction and strength of the linear relationship between selected elements of digitalisation and good governance principles. Finally, differences between the AUs were identified with regard to their size (i.e. 10 large AUs with over 50,000 inhabitants, 28 medium AUs with 18,000-50,000 inhabitants, and 20 small AUs).

\section{Results of digitalisation in Slovenian AUs}

Based on the survey results and their processing and comparison, the key findings on the scope and factors of AU digitalisation relative to Covid19 are now presented. In general, the Slovenian AUs report that during the crisis regulations and measures were adopted very quickly and in great numbers, which is comparable to other countries (cf. Sigma, 2020; Bouckaert, 2020). This resulted in certain inter-departmental inconsistencies as individual ministries often issued different instructions to the AUs, hence making it more difficult to ensure legality, efficiency, and work ethics (Aristovnik et al., 2020). The responses - which, checked against the control questions, are all consistent - suggest several starting points for better system resilience in the future.

On average, among the principles of good governance, the respondents somewhat surprisingly (cf. Table 1 ) highlighted the importance of accountability (3.76 out of 5 , that is, above the level in normal operations) and responsiveness (3.38), but less so legality (2.95) and participation (2.81). The combination of legally supported and digitalised operation proved to be a positive response to the crisis. As a result, the use of e-mail ( 4.78 with public services users vs. 3 in normal operations), e-portals (4.17) and videoconferencing (3.84) increased significantly.

Increased digitalisation between administrative bodies and public services users is largely reflected in the number of public services users taking advantage of the simplified forms of communication, on average up to 4.55 out of 5 compared to normal operations. This suggests that the users' expectations - in line with initial hypothesis $\mathrm{H} 1$ - are a fundamental driver 
of digitalisation. This is especially true for e-applications, e-hearings, and e-services, with very few problems or misuses being reported, although the AUs reported a considerably greater workload due to simplifications (as much as 3.95). ${ }^{5}$ This outcome is probably due to the exceptional circumstances of the first wave of Covid-19 in spring, when it took some time for the staff to shift over to such a manner of work. However, a similar share is also expected in normal circumstances.

\section{Figure 1: CORRELATION HEATMAP ON DIGITALISATION VS. GOOD GOVERNANCE PRINCIPLES - ALL AUS}

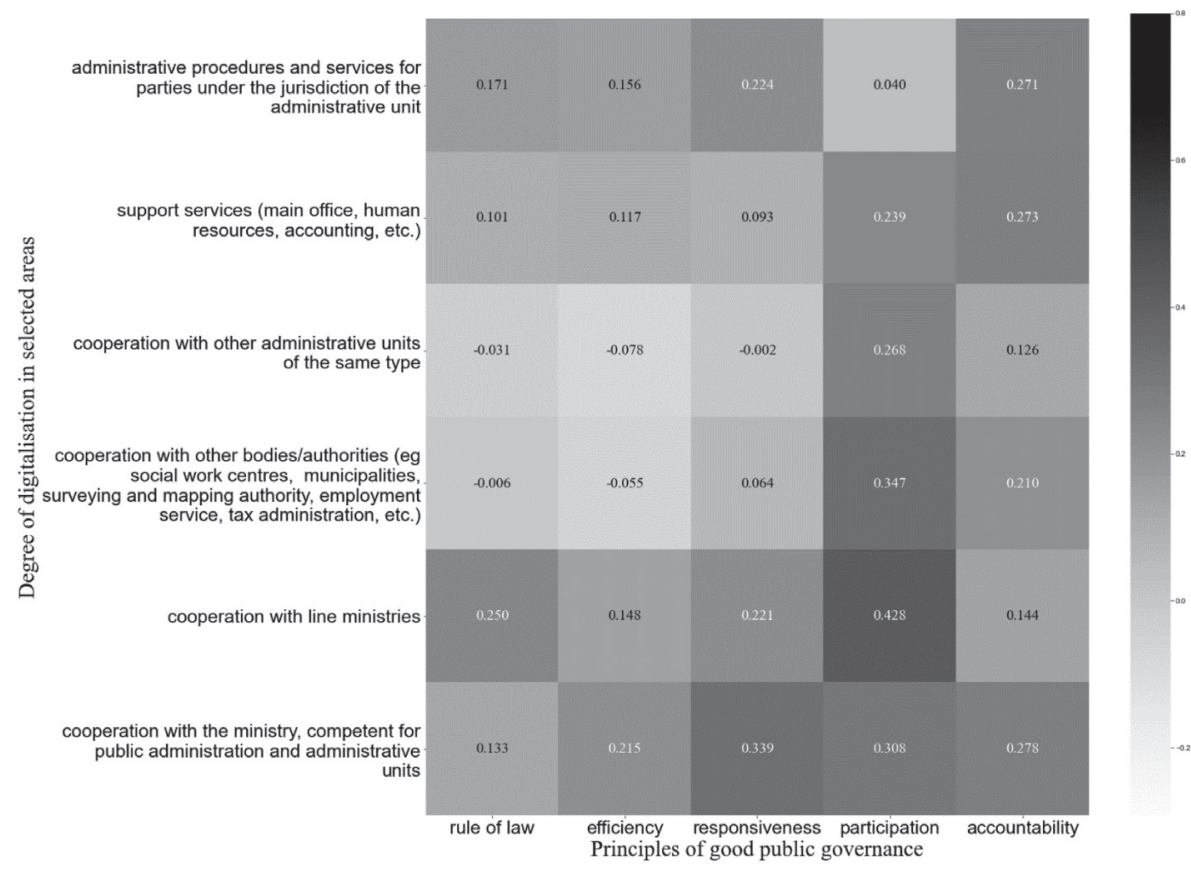

Note: 1) Vertical items: For the time of the epidemic, compared to normal operations, please estimate the degree of digitalisation of the administrative unit in the areas listed below. 2) Horizontal items: For the time of the epidemic, compared to normal operations, please estimate the orientation of legislation, guidelines and instructions (measures) to the following principles of good public governance. 3) Items are measured on a five-point Likert scale: 1 significantly smaller, 2 - smaller, 3 - equal, 4 - higher, 5 - significantly higher.

Source: own analysis.

5 The distribution of interest by type of procedure was slightly different from normal operations as most public services users' applications concerned internal affairs (e.g. registration of residence or permits for foreigners). But, in just a few weeks, this also spread e.g. to construction or agriculture, which means the results may be considered representative for the post-pandemic time. Problems were largely reported concerning the running of deadlines (almost one-third more than normally). This relates exclusively to the specifics of the Covid-19 Act, which provided for the suspension of deadlines in non-urgent matters, but not for the various statuses held by public services users as the parties or for most building permits. 
Further, correlation analysis (calculation of Spearman rank correlations between selected pairs of statements) was performed to assess the increase in internal and external digitalisation (Aristovnik et al., 2020) so as to gain insight into the differences between the AUs by size and coverage area (urban or rural) in conjunction with the principles of good governance pursued (including the five most prominent ones). The results of the analysis presented in Figure 1 show correlation between the extent of digitalisation and the principles of good governance across the entire AU sample. Figures 2 and 3 refer to large and medium-sized AUs and reveal differences in the degree of digitalisation by size. In this case, the small AUs were disregarded due to a lack of significant correlations. The darker boxes express stronger correlation, with the limit set at 0.6. This limit was not recorded by any AU, as the highest correlation of 0.428 was achieved in digitalised cooperation between the AUs and line ministries, which suggests the considerable relevance of the top-down guidelines.

Surprisingly - considering that the AUs operate uniformly, under the same regulations and guidelines issued by the line ministries and the MPA - considerable differences relate to the size of an AU, as shown in Figures 2 and 3 that

Figure 2: CORRELATION HEATMAP - LARGE AUS

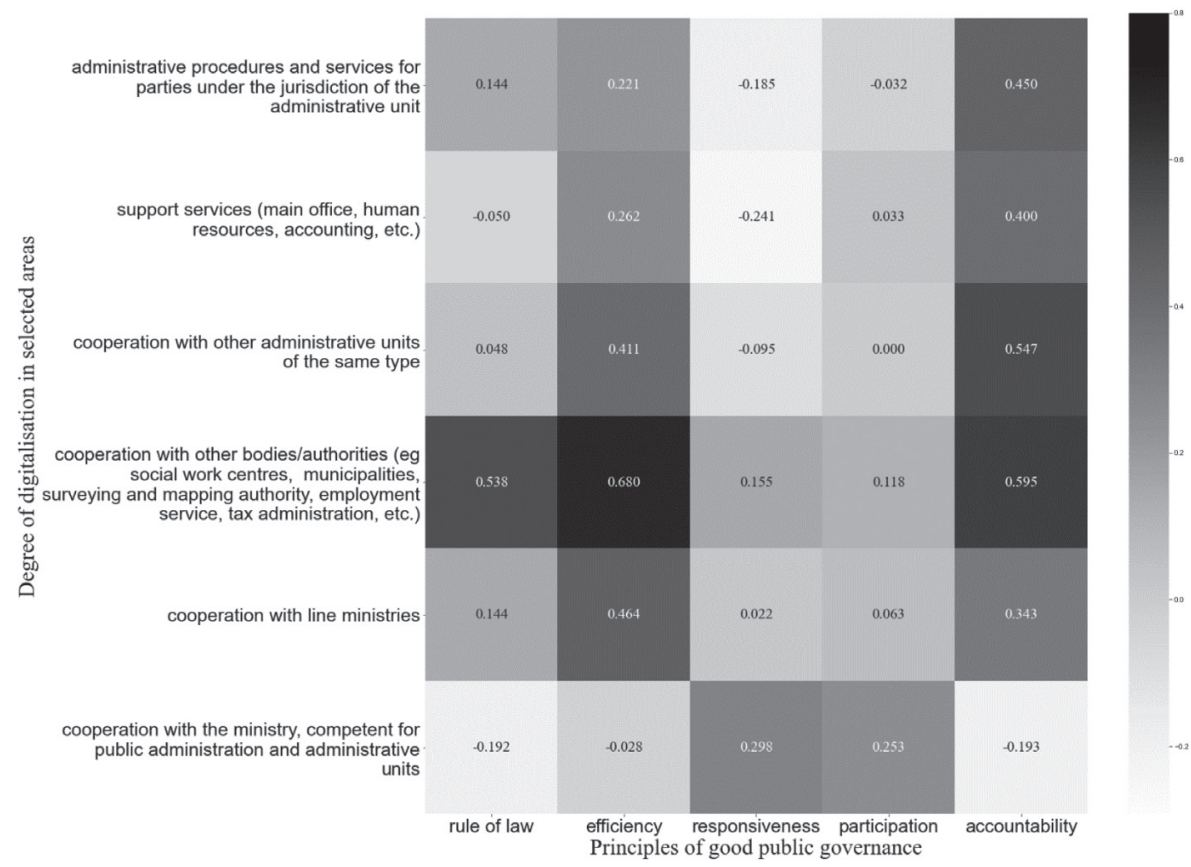

Note: Vertical and horizontal items as well as the five-point Likert scale are the same as under Figure 1.

Source: own analysis. 
give additional information on small AUs. A higher number of inhabitants, cases and staff, coupled with a broader coverage area (mainly urban in the case of large AUs) all seem to have a significant positive impact on digitalisation. In other words, the more concentrated the territory of an AU and thus the larger the $\mathrm{AU}$, the higher the expectations of the public services' users for digitalisation, to which the AUs respond promptly and proactively.

A strong correlation with a value above 0.6 is to be discerned in only a few cases and almost exclusively in large and medium-sized AUs. In large AUs, efficiency and accountability ( 0.680 and 0.595 , respectively) stand out, especially in digitalised cooperation with other bodies. This is indeed an advantage for the users as their life situations are solved together with other bodies. Further analysis of correlation depending on the coverage area, noting that large AUs are more urban-oriented, shows that the correlation between digitalised relations and the GG principles is significantly stronger in the cities, namely, 6 out of 30 correlations (e.g. between accountability towards support digitalised services and other bodies (approximately 0.7 ), and responsiveness (0.648) and efficiency (0.636) through digitalised relations with line ministries).

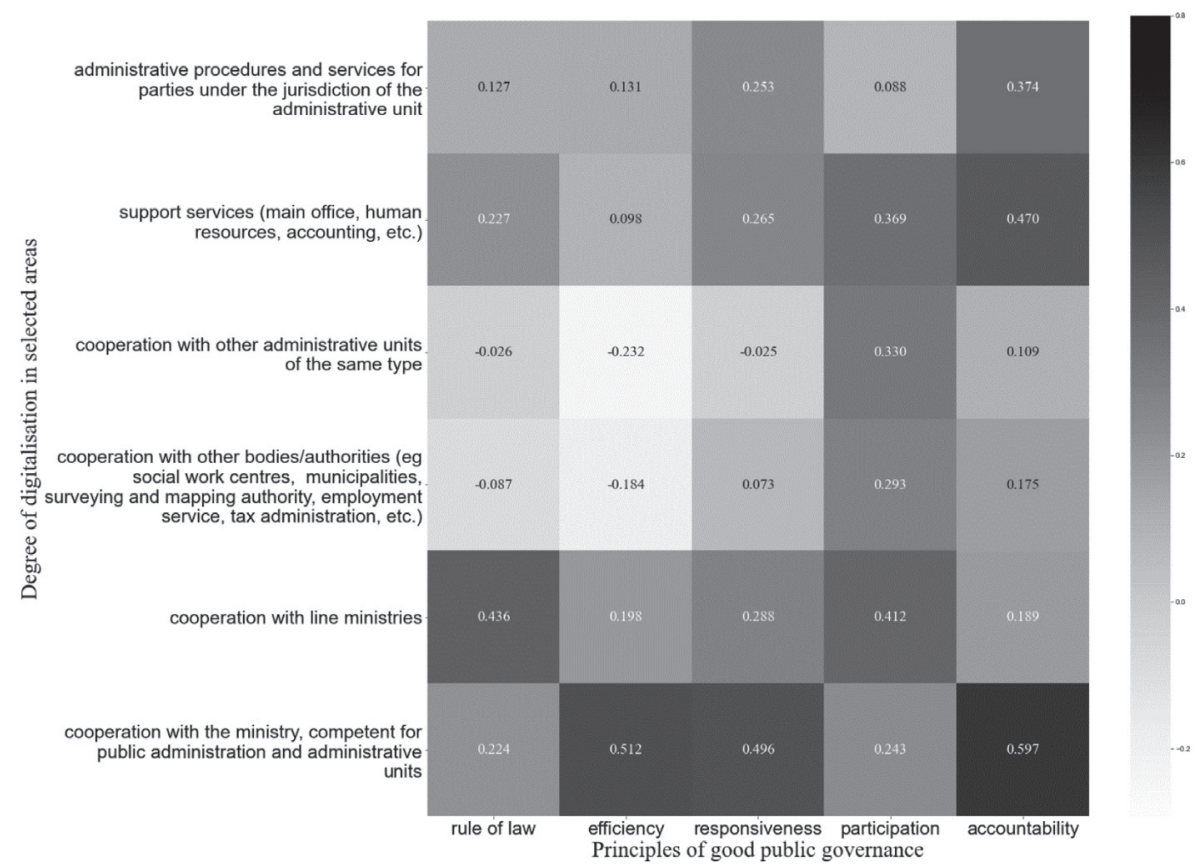

Note: Vertical and horizontal items as well as the five-point Likert scale are the same as under Figure 1.

Source: own analysis. 
For medium AUs (Figure 3 above), the strongest correlations are again observed in accountability (0.597) and responsiveness (0.496) for digitalisation, but only to the superior MPA, while the correlation in digitalised services for users mainly hovers around 0.2 for almost all principles. In the case of small AUs, values over 0.6 can only be found in the correlation with digitalised cooperation with other bodies. Finally, we identified the main elements to be enhanced with respect to digitalisation in the future (Figure 4).

Figure 4: POST-PANDEMIC LIKELIHOOD OF COVID-19 INNOVATIONS

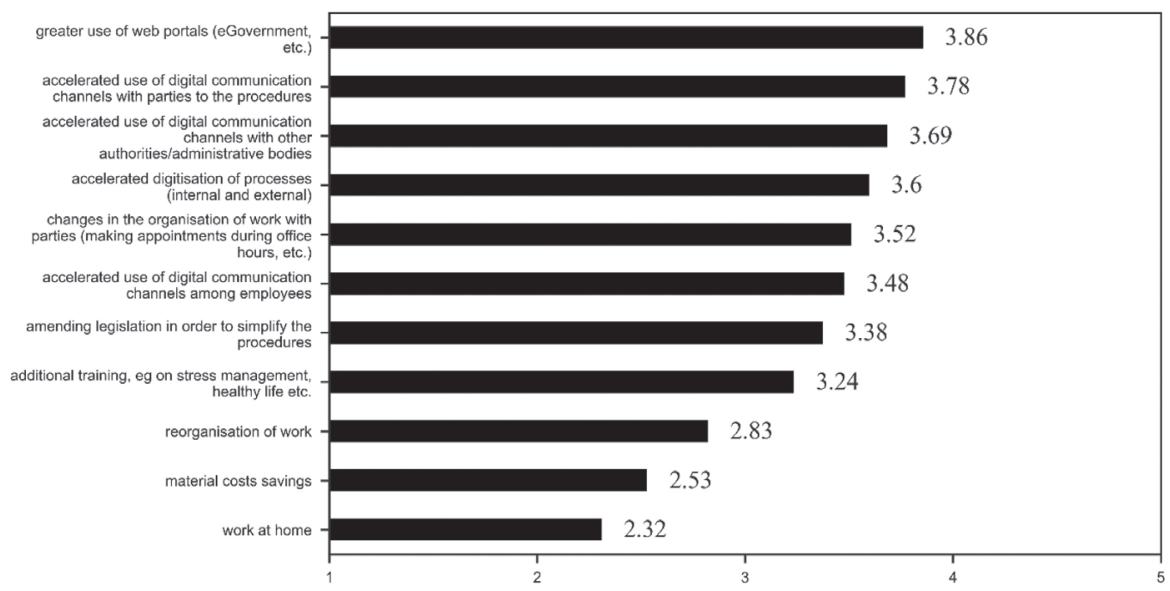

Note: 1) Vertical items: Estimate the probability that the following changes will remain or will be introduced (also) after the epidemic. 2) Items are measured on a five-point Likert scale: 1 - not likely at all, 2 - low probability, 3 - middle probability, 4 - likely, 5 - very likely. Source: Aristovnik et al., 2020.

\section{Discussion}

The results of the survey among Slovenian AUs confirm the initial hypotheses. According to H1, the biggest drivers of digitalisation are the expectations and needs of the public services users as parties to administrative procedures. Still, not every type of administrative body can cope with their demands, only those bodies large enough to ensure that the work is organised efficiently and responsively. Significant correlations between the principles of good governance and digitalised external or internal procedures in the AUs can primarily be found in the case of large AUs, especially for efficiency and accountability, which is similar to the results of analyses in other countries (cf. OECD, 2020; Misuraca et al., 2020). Even more significant correlations are found in urban AUs, which include large AUs and selected smaller units associated with city centres where the principle of 
responsiveness, directly to the superior ministries and indirectly to the services users, also stands out. In general, the AUs show a high level of accountability to public services users, but in the absence of top-down coordination the system does not work comprehensively and equally for all citizens and businesses as the principles of democratic governance require (Galetta et al., 2015; Avbelj, 2019). In this context, it is important to confirm H2 that the system's digitalisation must be based on relevant legal bases, whereas emergency laws as examples of good practices can serve as lasting solutions in the GAPA.

In a theoretical sense, good governance underscores the importance of various principles. However, these only function if all act as pieces of the same puzzle. Hence, it is not surprising to empirically confirm - with regard to Covid-19's impact on digitalisation - that public services users are stimulating the authorities' responsiveness, but the authorities must still strike a balance between public and private interests (Kovač et al., 2016: 142; Aristovnik et al., 2020: 7). Speeding up the procedures at the expense of the constitutional guarantees of the public services users is counterproductive since it is likely to result in judicial reviews and the abrogation of administrative acts (Avbelj, 2019; Auby, 2014). A comparison with other analyses 664 conducted in the EU (Sigma, 2020; Misuraca et al., 2020; Bouckaert et al., 2020) shows that despite the, in principle, positive digitalisation, there are specific caveats. First, care must be taken to ensure that the infringement of people's rights is temporary and proportionate, despite the need for a speedy response in a crisis. Second, it is necessary to assure not only the reactivity but also the resilience of a proactively guided top-down approach at the low levels of administrative service delivery. This is true in both organisational and legal terms. Third, systemic digitalisation is an innovative and lasting solution, but only when coupled with the awareness of the specifics of administrative matters. Efficiency should indeed prevail over lawfulness, otherwise a boomerang effect will ensue, e.g. through court disputes. The technological perspective is less important than a longstanding administrative system that enables and perpetuates or hinders digitalisation and innovation. When digital technology meets traditional bureaucracy, the result is not always less bureaucracy (Ranchordas, 2020). Law, together with a traditionally bureaucratic culture and non-agile or only partially organisational approaches, is more a barrier than a driver of digitalisation. In such conditions, it is not about promoting good governance and innovation, but about lowering constitutional rights, EU principles, and the democracy of authority.

Summarising the research results, it may be concluded that Slovenian AUs have not (yet) reached the level of digital transformation 4.0 (Misuraca, 2019: 8-19). They are not (yet) fully implementing the principles of good 
governance, although the procedures and procedural actions are gradually evolving into citizen-centred smart governance. In this setting, crises represent both a problem and an opportunity for progress. However, due to increasing differences, it is precisely in a crisis that services and procedures on the state level must pay attention to equality and balancing between legal rights and the public interest with efficiency-oriented measures. What seem to be shortcuts - e.g. wide acceptance of e-applications without legally supported requirements and the consequences of any violations thereof - can even be harmful if legal guarantees are lowered because they are perceived as administrative barriers. To avoid this, it is necessary to be aware of both existing and future pluses and minuses, as shown by the SWOT analysis (Table 2).

\section{Table 2: SWOT ANALYSIS OF COVID-19'S IMPACT ON DIGITALISATION IN AUS}

\section{Strengths (current advantages):}

- public services users' expectations in the context of the globalisation of business and governance in the EU and beyond;

- although rigid, regulation under the GAPA complies with the international principles of a fair trial, but considering the emergency laws, the simplifications in question are possible without abuse by the users;

- the existing portals (e-Government) enable systemically digitalised internal and external communication;

- a functioning system of justice for the protection of public services users' rights, which otherwise restricts digitalised solutions if they infringe the rights of defence.

Opportunities (possible future advantages):

- understand digitalisation as a tool for greater efficiency and participation in administration, not one at the expense of the other; set the strategy and investments accordingly;

- organise the AUs into larger organisations, with a critical mass of response to users' needs; so that digitalisation is taken as a means of better distributional justice;

- connect internal and external e-communication channels;

- transpose the solutions enshrined in emergency laws regarding e-applications, e-service, e-hearings etc. into permanent codification;

- the GAPA as a driver of administrative modernisation for a resilient crisis response.
Weaknesses (current disadvantages):

- excessively formalised requirements for public services users in the digitalised procedural actions under the GAPA;

- an administrative culture that is not conducive to a principled interpretation of the GAPA, but expects to follow the letter of the law for any action in relation to the users;

- the entire GAPA's only partial suitability for all matters, while some simplifications beyond the Constitution;

- insufficient coordination among ministries; individual bodies operate bureaucratically, not as part of a system; certain units are too small;

- some procedures take (too) long.

Threats (possible future disadvantages):

- (too) low level of a proactive culture in the administration, the necessary topdown approach and within an individual unit from the head to the staff regarding the procedures' objectives, at the same time the public interest, but also servicemindedness;

- necessary strategic approach with partners;

- when changing the GAPA, a questionable impact on lex specialis; necessary parallel changes to the GAPA for constitutionally equal protection of rights;

- due to simplifications for the users, (too) heavy a workload for the authorities if the measures are too unilateral/partial;

- concerns related to privacy and trust.

Source: own analysis. 
The process of exercising administrative rights and obligations and the legal regulation thereof in the context of digitalisation and innovation in public administration should not be underestimated since it is the procedure that establishes the manner and scope of the desired outcome. It is through procedure that the legitimacy of the authorities is achieved, especially in times of crisis and fairness (Windholz, 2020: 102, 106). Yet, this does not mean that a law on innovations and digitalisation should be adopted. Instead, it is about explicitly allowing and encouraging administrative bodies to follow comparable innovative practices in the EU. It is true for the EU that the importance of the ICT revolution can scarcely be exaggerated as it has played a central role in buttressing the Commission's special position as a leader in network construction (Harlow and Rawlings, 2014: 25). After all, although law and institutions are static, thereby providing legal certainty and legitimate expectations, a law like the GAPA can indeed act to drive innovations in public administration. These are possible with a change in the traditionally formalistic mind-set, primarily among the leaders, as both the crises and innovations resulting from them are an antithesis to bureaucracy and require a new form of leadership (Prezelj and Doerfel, 2017; Greve et al., 2019). Thus, only a complex set of measures for the organisa-

666 tion and digitalisation of administrative work, its legal regulation and the construction of the socio-psychological aspects of service-mindedness can lead to sustainable progress.

\section{Conclusion}

Innovation in public administration as well as the digitalisation and codification of administrative procedures must be interpreted and further explored as complementary rather than conflicting concepts. The main reason for this is based on the understanding of administrative procedures as key processes for an inevitably responsive public administration in a modern and changing society and during crises. In this context, the initial research question of this study, addressing how Slovenia and its administrative units as local general authorities have responded to the pandemic, was tackled using various research methods. Their combination revealed that, although the response of all 58 Slovenian administrative units was not as unified as expected due to their centrally guided functions, it was mostly appropriate. The digitally supported communication in relation to public services' users was found to be particularly positive, the more so in larger units with greater resources. These authorities promptly followed the users' increased needs to run procedures online and in a less formal way. However, to improve the necessary resilience of public administration in times of a pandemic and similar crises, a more comprehensive approach 
is called for. First, not only external relations but also regularly digitalised internal coordination among various authorities are essential for overall digital transformation. Second, the responses of different authorities should be harmonised regardless of their size to offer citizens and businesses the same accessibility in urban and more rural areas alike. Third, the pandemic crisis was an exception with some temporary measures being experienced, while permanently digitalised solutions in public affairs demand innovations that are flexible yet simultaneously covered by certain legal safeguards. The latter need to disable or minimise any misuses in the less formal e-communication. Nevertheless, the Covid-19 circumstances have shown that digitalisation in public administration is nowadays an indispensable way forward globally.

In addition, the analyses of the work of the administrative units and digitalised procedures within the administration and externally towards public services users show that the effects are generally positive in terms of compliance with the principles of good governance. The essence of the legal regulation of public administration must not be formalisation due to prior distrust in public services users. Digitalisation should be systemically supported with appropriate legal mechanisms to protect users' rights and their legal certainty. Moreover, in the digital transformation, the importance of the organisation and cultural orientation of the heads and staff of the administrative units should not be underestimated, as only all of these aspects can ensure a resilient response to the current Covid-19 or any future crisis. Digital transformation therefore offers a holistic opportunity for the more sustainable governance of societal issues.

\section{BIBLIOGRAPHY}

Aristovnik, Aleksander, Polonca Kovač, Dejan Ravšelj, Nina Tomaževič and Lan Umek (2020): Vpliv epidemije covid-19 na učinkovitost javne uprave [Covid19 Impact on efficiency of AUs in Slovenia]. Ljubljana: Faculty of Public Administration.

Auby, Jean-Bernard (ed.) (2014): Codification of Administrative Procedure Brussels: Bruylant.

Avbelj, Matej (ed.) (2019): Komentar Ustave RS [Commentary of the Slovenian Constitution]. Nova Gorica: New University, European Law Faculty.

Bouckaert, Geert, Davide Galli, Sabine Kuhlmann, Renate Reiter and Steven S. Van Hecke (2020): European Coronationalism? A Hot Spot Governing a Pandemic Crisis. Public Administration Review 80 (5): 765-773.

Bučar, Maja and Metka Stare (2003): Inovacijska politika male tranzicijske države [Innovation Policy of Small Transition Country]. Ljubljana: Faculty of Social Sciences.

Croasmun, James T. and Lee Ostrom (2011): Using Likert-Type Scales in the Social Sciences. Journal of Adult Education 40 (1): 19-22. 
de Vries, Hanna, Victor Bekkers and Lars Tummers (2016): Innovation in the Public Sector: A Systematic Review and Future Research Agenda. Public Administration 94 (1): 146-166.

Hofmann, Herwig C. H., Jens-Peter Schneider and Jacques Ziller (eds.) (2014): The ReNEUAL Model Rules. Accessible at www.reneual.eu, 1. 11. 2020.

Galetta, Diana-Urania, Herwig C. H. Hofmann, Oriol Mir Puigpelat and Jacques Ziller (2015): The General Principles of EU Administrative Procedural Law. Brussels: EP.

Greve, Carsten, Niels Ejersbo, Per Lagreid and Lise H. Rykkja (2019): Unpacking Nordic Administrative Reforms: Agile and Adaptive Governments. International Journal of Public Administration 43 (8): 697-710.

Harlow, Carol and Richard Rawlings (2014): Process and Procedure in EU Administration. Oxford, Portland, Oregon: Hart.

Koprić, Ivan (1999): Struktura i komuniciranje u upravnim organizacijama [Structure and Communication in Administrative Organisations]. Zagreb: Faculty of Law.

Koprić, Ivan, Polonca Kovač, Vedran Đulabić and Jasmina Džinić (2016): Legal Remedies in Administrative Procedures in Western Balkans. Danilovgrad: ReSPA.

Kovač, Polonca (2016): The Requirements and Limits of the Codification of Administrative Procedures in Slovenia according to European Trends. Review of Central and East European Law 41 (3/4): 427-461.

Kovač, Polonca (2020): Codification of the Administrative Procedure in Slovenia and the EU: Yesterday, Today and Tomorrow. Teorija in praksa 57 (3): 848-866.

Kovač, Polonca, Nina Tomaževič, Anamarija Leben and Aleksander Aristovnik (2016): Reforming Public Administration in Slovenia: Between Theory and Practice of Good Governance. International Journal of Public Policy 12 (3/4/ 5/6): 130-148.

Kovač, Polonca and Erik Kerševan (eds.) (2020): ZUP s komentarjem, 1, 2 [General Administrative Procedure Act with Commentary, 1 and 2]. Ljubljana: Uradni list RS.

Kukovič, Simona and Gorazd Justinek (2020): Modernisation Trends in Public Administration in Slovenia. Croatian and Comparative Public Administration 20 (4): 623-647.

Little, Roderick J. A. and Donald B. Rubin (2019): Statistical Analysis with Missing Data (793). John Wiley and Sons.

Massey, Andrew (ed.) (2019): A Research Agenda for Public Administration. Cheltenham, Northampton: Elgar.

Metzger, Gillian (2015): Administrative Law, Public Administration, and the Administrative Conference of the US. The George Washington Law Review 83 (4/5): 1517-1539.

Miller, Gerald J. (ed.) (1998): Handbook of Research Methods in Public Administration (vol. 134). CRC press.

Misuraca, Gianluca (ed.) (2019): Exploring Digital Government Transformation in the EU. Analysis of the State of the Art and Review of Literature. Luxembourg: Publications Office of the EU. 
Misuraca, Gianluca, Egidijus Barcevičius and Cristiano Codagnone (eds.) (2020): Exploring Digital Government Transformation in the EU. Understanding Public Sector Innovation in a Data-driven Society. Luxembourg: Publications Office of the EU.

Prezelj, Iztok and Marya L. Doerfel (2017): Resilience in a Complex and Unpredictable World. Journal of Contingencies and Crisis Management 25 (3): 118-122.

Ranchordas, Sofia (2020): Bureaucracy and Vulnerability in the (Digital) Administrative State. Int'l J. Const. L. Blog. Accessible at http://www.iconnectblog. com/2020/09/bureaucracy-and-vulnerability-in-the-digital-administrative-state/, 1. 11.2020.

Rose-Ackerman, Susan, and Peter L. Lindseth (eds.) (2010): Comparative Administrative Law. Northampton, Cheltenham: Elgar.

Rusch, Wolfgang (2014): Citizens First: Modernisation of the System of Administrative Procedures in South-Eastern Europe. Croatian and Comparative Public Administration 14 (1): 189-228.

Stewart, Richard B. (1981): Regulation, Innovation, and Administrative Law: A Conceptual Framework. California Law Review 69 (5): 1256-1377.

Torfing, Jacob and Peter Triantafillou (eds.) (2016): Enhancing Public Innovation by Transforming Public Governance. Cambridge: Cambridge University Press.

Van der Hof, Simone and Marga M. Groothuis (eds.) (2011): Innovating Government. Normative, Policy and Technological Dimensions of Modern Government. The Hague: Asser Press.

van Acker, Wouter and Geert Bouckaert (2017): What Makes Public Sector Innovations Survive? An Exploratory Study of the Influence of Feedback, Accountability and Learning. International Review of Administrative Sciences 84 (2): 249-268.

Vigoda, Eran (2002): From Responsiveness to Collaboration: Governance, Citizens, and the Next Generation of Public Administration. Public Administration Review 62 (5): 527-540.

Windholz, Eric L. (2020): Governing in a Pandemic: From Parliamentary Sovereignty to Autocratic Technocracy. The Theory and Practice of Legislation 8 (1-2): 93-113.

\section{SOURCES}

OECD (2020): Digital Government Review of Slovenia. Accessible at https://www. oecd.org/gov/digital-government/digital-government-review-of-slovenia-2020. htm, 25. 11. 2020.

Sigma (2020): Public Administration: Responding to the Covid-19. Accessible at http://www.sigmaweb.org/publications/SIGMA-mapping-public-administration-response-EU-members-coronavirus-COVID19.pdf, 1. 11. 2020.

Venice Commission (2011): Stocktaking on the Notion of Good Governance and Good Administration. Study 470/2008, CDL-AD(2001)009. 